\title{
Comprehensive study of morbidity in school going children in rural areas of western Rajasthan
}

\author{
S.K. Vishnoi ${ }^{1}$, Rakesh Jora ${ }^{2}$, Sandeep Choudhary ${ }^{3, *}$, Praveen Chopra ${ }^{4}$ \\ ${ }^{1,3}$ Assistant Professor, ${ }^{2,4}$ Senior Professor, Dept. of Pediatrics, Dr. S.N. Medical College, Jodhpur, Rajasthan, India
}

*Corresponding Author:

Email: sandeepbugasara@gmail.com

\begin{abstract}
Introduction: School age children (5-15 years) have not received as much attention from health providers/planners as the under fives. In India, several studies have been carried out on the health status of school age children. We have conducted to evaluate the extent and pattern of health status of school age children in village of Western Raiasthan bv a mobile health team.

Methods: This cross sectional epidemiological study was carried out in Osian block of Jodhpur district of Western Rajasthan over a period of one year. Medical officer and paramedical staff documented demographic and anthropometric data, including height, weight mid upper arm circumference, chest circumference, waist-circumference and blood pressure. Para medical staff was trained specifically for taking anthropometry and blood pressure in children.

Results: Over a period of one year total 11651 children were screened. Dental carries was the most common problem followed by vision impairment and language delay (Table 1). Both males and females were equally affected $(p>0.05)$. The overall intake of calories, iron, riboflavin, niacin and vitamin A was significantly less ( $p<0.05$ ) than the recommended dietary allowance (RDA). Majority (52\%) of the children were taking calorie and protein between $50-75 \%$ of requirement

Conclusion: Educating the community about common diseases in children and their impact on the health of school age children, their etiology and prevention will go a long way in improving the quality of life of these children. By early detection and referral facility, there is less chances of complication of disease and better outcome of disease.
\end{abstract}

Keywords: School age children, Dental caries, Anthropometry.

\section{Introduction}

School age children (5-15 years) have not received as much attention from health providers/planners as the under fives. In an international workshop at Kentucky, USA in 1994, it was agreed that there was a dearth of information on the health status of school age children from developing countries particularly at the community level. ${ }^{1}$ In India, several studies have been carried out on the health status of school age children. These have largely been quantitative and the reported morbidity included malnutrition (10.0-98.0\%), dental ailments (4.0-70.0\%), worm infestation (2.0-30.0\%), skin diseases $(5.0-10.0 \%)$, eye diseases $(4.0-8.0 \%)$, and anaemia $(4.0-15.0 \%) .^{2-14}$ However, data on the community's perception about these morbidities are inadequate. It is now being increasingly recognized that proper understanding of the community's view point of any health problem contributes significantly towards formulating and implementing strategies that improve their health. Delineation of pattern and frequency of diseases in school children will help in formulating policies at community level. With this background, this study was conducted to evaluate the extent and pattern of health status of school age children in village of Western Rajasthan by a mobile health team.

\section{Methodology}

This cross sectional epidemiological study was carried out in Osian block of Jodhpur district of Western Rajasthan over a period of one year. The block includes 28 villages with a total population of 80,000 .
Most of the villagers of are either landless agricultural labourers or weavers and were socioeconomically backward with an average per-capita income of Rs. $2,201 \pm 36$ (US $\$ 50 \pm 0.7$ ) per annum. The estimated number of children age 5 to 15 years attending the various schools are approximately 88000 . We randomly selected 20 out 28 villages and enrolled all the children studying in both government and private schools of these villages.

Consent to take part in the study was taken from the teachers and students. During the survey, a mobile team including a medical officer, and a paramedical staff, screened all the enrolled children. History, physical examination and systemic examinations were done by the medical officer and paramedical staff documented demographic and anthropometric data, including height, weight mid upper arm circumference, chest circumference, waist-circumference and blood pressure. Para medical staff was trained specifically for taking anthropometry and blood pressure for this study. Examination tools included Snellen eye chart, torch, measuring tape, hammer, stethoscope, sphygmomanometer, tongue depressor, otoscope and nasal speculum.

\section{Results}

Over a period of one year total 11651 children were screened, out of which 5727 were males and 5924 were females. Two hundred and three children were referred to higher centre for further management. Dental carries was the most common problem followed 
by vision impairment and language delay (Table 1). Both males and females were equally affected ( $p$ $>0.05)$.

Table 1: Distribution of the children according to calorie and protein Intake

\begin{tabular}{|l|c|c|}
\hline S.No. & $\begin{array}{c}\text { Calorie and Protein (\%) } \\
\text { requirement) }\end{array}$ & Number (\%) \\
\hline 1 & Les s than $50 \%$ & $4427(38 \%)$ \\
\hline 2 & $50-75 \%$ & $6058(52 \%)$ \\
\hline 3 & More than $75 \%$ & $1166(10 \%)$ \\
\hline 4 & Total & 11651 \\
\hline
\end{tabular}

As regards to cause of morbidity, many of them said that they did not know what caused these morbidity. Some felt that change of water, exposure to cold, intake of food that did not agree with the body, excessive heat in the body, fear, eye problems and poor hygiene caused some of the morbidity in school age children. For instance, many believed that bathing in tap-water one day and in surface water another day would cause respiratory infection.

The overall intake of calories, iron, riboflavin, niacin and vitamin A was significantly less ( $p<0.05)$ than the recommended dietary allowance (RDA) while that of protein and thiamine was not so. Table 2 shows the distribution of the children according to calorie and protein Intake in screened population.

Majority (52\%) of the children were taking calorie and protein between $50-75 \%$ of requirement. The mean calories deficit in the study group was $601 \pm 112$ kcal of their expected weight of age $(p<.05)$.

The mean heights and weights of children were compared with the National Centre for Health Statistics, in both girls and boys these were found to be less than the reference standards. The under nutrition is more prevalence then obesity. $27.7 \%$ of study group were in between 2SD and 3SD of less than 5 year of age group and $19 \%$ of age group more then 5 year were BMI less then 18.5. The mean height of the study group was $82 \%$ of expected height of that age. Majority were normotensive. Table 2 shows the distribution of screened population according to weight for height.

Table 2: Distribution of children according to weight for height

\begin{tabular}{|l|c|c|}
\hline S.No. & $\begin{array}{c}\text { Weight for Height } \\
(\boldsymbol{\%})\end{array}$ & Number (\%) \\
\hline 1 & $40-50$ & $466(4 \%)$ \\
\hline 2 & $50-55$ & $4428(38 \%)$ \\
\hline 3 & $55-60$ & $2563(22 \%)$ \\
\hline 4 & $60-65$ & $3262(28 \%)$ \\
\hline 5 & $65-$ less than 70 & $932(8 \%)$ \\
\hline
\end{tabular}

Majority of children $38 \%$ had weight for height between $50-55 \%$ followed by $28 \%$ between $60-65 \%$. Whose refer to higher centre $85.2 \%$ cases was in between $50-55 \%$ of weight for height. Table 3 shows the list of morbidity in school age children whose refer to higher centre.

Table 3: Morbities in school children

\begin{tabular}{|l|c|c|}
\hline \multicolumn{1}{|c|}{ Morbidity } & $\begin{array}{c}\text { Number of } \\
\text { children }\end{array}$ & Prevalence \\
\hline DentalCaries & 72 & $23.8 \%$ \\
\hline Vision Impairment & 26 & $8.6 \%$ \\
\hline Language delay & 13 & $6.4 \%$ \\
\hline Hearing impairment & 9 & $4.4 \%$ \\
\hline Behavioural dis order & 4 & $1.9 \%$ \\
\hline $\begin{array}{l}\text { Neuro-motor } \\
\text { impairment }\end{array}$ & 5 & $2.4 \%$ \\
\hline Learningsdisorder & 3 & $1.4 \%$ \\
\hline Skin condition & 11 & $5.4 \%$ \\
\hline $\begin{array}{l}\text { Rheumatic heart } \\
\text { disease }\end{array}$ & 3 & $1.4 \%$ \\
\hline Motor delay & 2 & $0.98 \%$ \\
\hline Otitis media & 7 & $3.4 \%$ \\
\hline Convulsive dis order & 2 & $0.98 \%$ \\
\hline Vitamin A deficiency & 7 & $3.4 \%$ \\
\hline Anaemia & 10 & $4.9 \%$ \\
\hline SAM/Stunting & 7 & $3.4 \%$ \\
\hline s Early rickets & 3 & $1.4 \%$ \\
\hline Others & 19 & $9.3 \%$ \\
\hline Total & 203 & \\
\hline
\end{tabular}

In India school health program through NRHM really works. The prevalence of disease is decreases. diarrhoea and respiratory infection are reduced $30 \%$ to $50 \%$, the progression of dental caries is reduced by $40 \%$ to $50 \%$, the prevalence of parasitic infestation reduced by $80 \%$, skin manifestation is reduced by $25 \%$, vitamin A deficiency reduced to $30 \%$ to $40 \%$, the number of children with below normal height and weight reduced to $20 \%$ all the diseases were reduced in comparison with previous year.so we can say, that school health program through NRHM really works.

\section{Discussion}

The success of child survival programmes and the expansion of basic education coverage resulted in a greater number of children reaching school age with a higher proportion actually attending primary school. However, there is increasing evidence, with resulting international concern, that the high level of nutritional deprivation combined with the heavy burden of dis ease in this age group has negative consequences for a child's long term development. This has prompted an increased focus on the diverse needs of the school-age child. The study of anaemia and other morbidity pattern may provide a clear and in depth idea about the problems in childhood age group. An attempt to paint a picture of nutritional status and morbidity status in school aged children in Delhi has been made in this study. Majority of children $38 \%$ had weight for height between $50-55 \%$ followed by $28 \%$ between $60-65 \%$. 
Prevalence of anaemia was found to be $4.9 \%$ these need for referral (Table 3).

The prevalence of anaemia in the similiar studies Ananthakrishnan S et al (7), Chakma T et al (8), Verma A et al (9), Handa $\mathrm{R}$ et al (10), and Bhoite $\mathrm{R}$ et al (11) Rema $\mathrm{N}$ et al (12) varies from $26 \%$ to $81.8 \%$ the prevalence of anaemia is higher in girls compared to boys in all of the studies; this finding was almost similar to the findings in present study. It was found that as the severity of anaemia increase the proportion of morbidity also increases. All children with severe anaemia had other co morbidities. This may be due to the fact that anaemic children become susceptible to secondary infections. (Table 3) The top six morbidities like dental carries $23.85 \%$, vision impairment $8.6 \%$ language delay $6.4 \%$ hearing impairment $4.4 \%$, skin conditions $5.4 \%$ and others $9.3 \%$ were need for refer to higher centre. The top morbidity found in girls was anaemia (83.9\%), malnutrition $(66.7 \%)$, diarrhoea $(33.7 \%)$, injury $(33.3 \%)$, worm infestation $(29.1 \%)$ and refractive errors $(28.8 \%)$. The pattern of morbidities as seen in boys and girls was almost equal except anaemia which more common in girl.

Shakya S R et al (13) in a cross-sectional study among primary school children in eastern Nepal observed that the most common morbidity was parasitic infestation $65.8 \%$ followed by malnutrition (61\%), anaemia $(58 \%)$, and other disorders were skin diseases (20\%), dental caries (19.8\%) and lymphadenopathy (10.5\%). Dambhare D G et al (14) in a study among the school going adolescents in peri-urban area of Wardha, found $51.7 \%$ was underweight, $28.45 \%$ anaemic, with girls suffering significantly more, dental caries was found in $35.3 \%, 13.8 \%$ were suffering from refractive error, $7.7 \%$ with worm infestation, $6.9 \%$ had skin problems, $2.5 \%$ had tonsillitis and $2.5 \%$ had wax in the ear which was comparable to our study. In the present study the spectrum of morbidity is wider and includes all systems. Most of the morbidities are preventable and treatable but if neglected can lead to chronic diseases which in turn may lead to irreversible disabilities.

\section{Conclusion}

It was observed that due to implementation of mid day meal program, provision of micronutrients, weekly provision of Iron Folate tablets, administration of Vitamin A in a needy, sanitary facility in school by NRHM, markedly decrease in prevalence of disease in rural area.

1. This study has shown that what the community perceives as morbidity among school age children is different from the morbidity observed in them on clinical examination. The community is also not aware of the etiology of many of these morbidities. Therefore, educating the community about these conditions and their impact on the health of school age children, their etiology and prevention will go a long way in improving the quality of life of these children.

2. People are not aware of the etiology of many of these disorders It is important to educate the community about the important morbidity in school age children, their etiology and prevention.

3. By early detection and referral facility, there is less chances of complication of disease and better outcome of disease.

\section{References}

1. Partnership for Child Development (1998), "The anthropometric status of school children in five countries in the Partnership for Child Development". Proceedings of the Nutrition Society 57:149-158.

2. World Health Organization (WHO). WHO global database on anaemia: Worldwide prevalence of anaemia 1993-2005. Geᄀneva: WHO, 2008a. [Cited 2014 Aug 24].

3. World Health Organization (WHO). Health in Asia and the Pacific: Reproductive health, child and adolescent health, nutrition, and health for older persons. Geneva: WHO, 2008b. [Cited 2014 Jul 6]

4. World Health Organisation. Criteria Anaemia 1985;WHO. World Bank.

5. National Family Health Survey (NFHS-3) (2005-06), Nutrition in India, Ministry of Health and Family Welfare Government of India.

6. World Health Organization. Anaemia. WHO (2010).

7. Ananthakrishnan S, Pani SP, Nalini P. A comprehensive study of morbidity in school age children. Indian Pediatr. 2001;38:1009-17.

8. Chakma T, Rao PV, Tiwary RS. Prevalence of anemia and worm infestation in tribal areas of Madhya Pradesh. $J$ Indian Med Assoc 2000;98:567, 570-571.

9. Verma A, Rawal VS, Kedia G, Kumar D, Chauhan J. Factors influencing anemia among girls of school going age (6-18 years) from the slums of Ahmedabad City. Indian Journal of Comm unity Medicine Jan.- Mar. 2004;29 (1):25-26.

10. Handa, R., Ahamad, F., Kesari, K. and Prasad, R. (2008) Assessment of Nutritional Status of 7-10 Years School Going Children of Allahabad District: A Review, MiddleEast Journal of Scientific Research 3 (3):109-115, 2008.

11. Bhoite R and Iyer U. "Magnitude of malnutrition and iron deficiency anemiaamong rural school children: an appraisal," Asian Journal of Experimental Biology Science, vol. 2, no. 2, pp. 354-361, 2011.

12. Rema N, Vasanthamani G. Prevalence of nutritional and lifestyle disorders among school going children in urban and rural areas of Coimbatore, T amilnadu: Indian Journal of Science and Technology 2011; Vol. 4 (2).

13. Shakya SR, Bhandary S and PokharelPK. Nutritional status and morbidity pattern among governmental primary school children in the eastern Nepal. Kathmandu Univ Med J 2004;2:307-14.

14. Dambhare DG, Bharambe MS, Mehendale AM, Garg BS. Nutritional Status and Morbidity among School going Adolescents in Wardha, a Peri-Urban area. Online $J$ Health Allied Scs. 2010;9(2):3. 